\title{
Microstructure and properties of mechanical alloying particles reinforced aluminum matrix composites prepared by semisolid stirring pouring method
}

\author{
Yao-qiang Si, *Zhi-yong You, Jing-xin Zhu, Lai-qiang Cai, and Jin-shan Zhang \\ College of Materials Science and Engineering, Taiyuan University of Technology, Taiyuan 030024, China
}

\begin{abstract}
Aluminum matrix composites reinforced with mechanical alloying particles $\left(\mathrm{SiC}_{\mathrm{p}}\right)$ were fabricated by the semisolid stirring pouring method. The influence of mechanical alloying particles and $\mathrm{Mg}$ on the microstructure and mechanical properties of the composites was investigated by means of optical microscopy (OM), X-ray diffraction scanning (XRD), electron microscopy (SEM) and energy dispersive spectroscopy (EDS). Results show that the addition of Mg converts the agglomerate mechanical alloying particles in ZL101 matrix composites into dispersed distribution in ZL101-Mg matrix composites, large matrix grains into fine equiaxed matrix grains, and eutectic phase into fine particles. So the mechanical properties of ZL101-Mg matrix composites are better than those of ZL101 matrix composites. The mechanical properties of ZL101/ZL101-Mg matrix composites are gradually increased with the increase of the volume fraction of mechanical alloying particles. When the volume fraction of mechanical alloying particles is $3 \%$, the Vickers hardness and ultimate tensile strength of the ZL101/ZL101-Mg matrix composites reach their maximum values.
\end{abstract}

Key words: mechanical alloying particle; aluminum matrix composites; grain refinement; mechanical properties

CLC numbers: TG146.21 Document code: A Article ID: 1672-6421 2016 03-176-06

Z 101 matrix composite has a wide application in the fields of aerospace and automobile, because of it's high specific strength, rigidity, wear resistance and good dimensional stability ${ }^{[1,2]}$. Because of low cost, good isotropic property and high wear resistance, ZL101 matrix composite reinforced with $\mathrm{SiC}_{\mathrm{p}}$ and fabricated by the semisolid stirring pouring method has received more attention from researchers ${ }^{[3-5]}$. Zhu Gang ${ }^{[6]}$ and Lu Jian ${ }^{[7]}$ have studied the microstructure and mechanical properties of ZL101 matrix composites with SiC particles in the range of 10 to $15 \mu \mathrm{m}$. Wang Hui et al ${ }^{[8]}$ have studied the microstructure and mechanical properties of aluminum matrix composites with $\mathrm{SiC}$ particles in the range of 20 to $50 \mu \mathrm{m}$. Zhou Yongxin et al ${ }^{[9]}$ have studied the microstructure, mechanical properties and wear resistance

\section{*Zhi-yong You}

Male, born in 1971, Ph.D., Associate Professor. His research interests mainly focus on magnesium and aluminum matrix composites and investment casting process.

E-mail: youzhiy1486@163.com

Received: 2015-10-23; Accepted: 2016-03-22 of aluminum matrix composites with $\mathrm{SiC}$ particles in the range of 70 to $150 \mu \mathrm{m}$. However, the microstructure and mechanical properties of ZL101 matrix composites reinforced with mechanical alloying particles in random distribution between 1 and $100 \mu \mathrm{m}$ have not yet been studied. Besides, it is well known that $\mathrm{Mg}$ element can improve the wettability of the composites, but few scholars pay attention to the study of the modification effects of $\mathrm{Mg}$ on eutectic phase and mechanical properties of ZL101 matrix composites. So in this study, the influences of mechanical alloying particles and $\mathrm{Mg}$ on the microstructure and mechanical properties were studied.

\section{Experimental procedure}

The matrix is ZL101 alloy with the mechanical alloying particles as the reinforcement phase. The mechanical alloying particles were obtained by ball-milling $\mathrm{SiC}$ particles with a particle size of $80 \mu \mathrm{m}$ mixed with 20 vol. $\%$ aluminum particles $(50 \mu \mathrm{m})$ for $2 \mathrm{~h}$ at a rotating speed of $300 \mathrm{r} \cdot \mathrm{min}^{-1}$ in a planetary mill. The contents of $\mathrm{Mg}$, mechanical alloying particles $\left(\mathrm{SiC}_{\mathrm{p}}\right)$ and ZL101 are listed in Table 1. 
Table 1: Nominal chemical compositions of experimental alloys (vol.\%)

\begin{tabular}{cccc|}
\hline No. & Mg & Particles & ZL101 \\
\hline $1 \#$ & 0 & 0 & Bal. \\
$2 \#$ & 0 & 1 & Bal. \\
$3 \#$ & 0 & 3 & Bal. \\
$4 \#$ & 3 & 0 & Bal. \\
$5 \#$ & 3 & 1 & Bal. \\
$6 \#$ & 3 & 3 & Bal. \\
\hline
\end{tabular}

The composites were prepared by semisolid stirring pouring method. Firstly, ZL101 alloy (and pure magnesium) was melted at $730{ }^{\circ} \mathrm{C}$ in the graphite crucible, and then the melt was cooled down to $600{ }^{\circ} \mathrm{C}$. Secondly, mechanical alloying particles that had been held for $2 \mathrm{~h}$ at $400{ }^{\circ} \mathrm{C}$ were slowly and evenly added into the melt with continuous stirring. Thirdly, after the addition of mechanical alloying particles, the mixed melt was stirred for $10 \mathrm{~min}$ by a stirrer at a rotating speed of $1,200 \mathrm{r} \cdot \mathrm{min}^{-1}$ and then rapidly heated to $730{ }^{\circ} \mathrm{C}$ before being poured into the steel mold (Fig. 1) preheated to $200{ }^{\circ} \mathrm{C}$. Finally, specimens for metallographic observation, hardness and tensile tests were taken from the middle of the ingot.

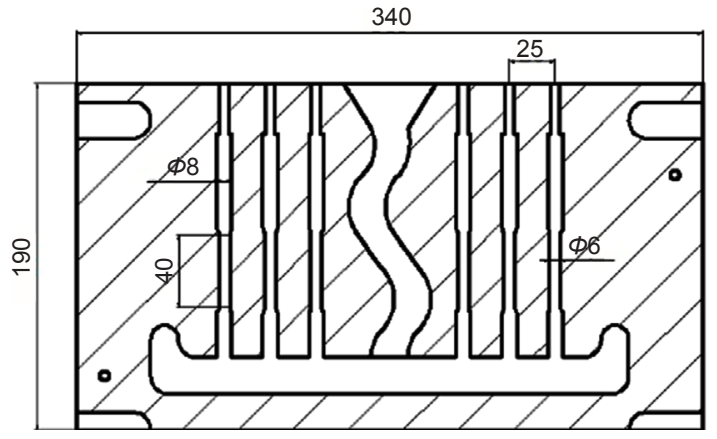

Fig. 1: Schematic diagram of steel mould

Optical microscopy (OM), X-ray diffraction scanning (XRD), electron microscopy (SEM) and energy dispersive spectroscopy (EDS) were used to observe the microstructure modification of the matrix alloy and the reinforcement particles distribution. Specimens for microstructure analysis were prepared by the conventional mechanical polishing and etching using $4 \% \mathrm{NaOH}$ for $10 \mathrm{~s}$. The average grain size of the matrix in the alloy and composites was measured using the mean linear intercept method. The microhardness of the matrix was confirmed on a HVS-1000A microhardness tester with a load of $0.98 \mathrm{~N}$ and a loading time of $15 \mathrm{~s}$. Tensile tests were performed on a DNS100 electronic universal material test machine at room temperature at a tensile rate of $0.5 \mathrm{~mm} \cdot \mathrm{min}^{-1}$

\section{Results and discussion}

\subsection{Microstructures}

Figure 2 shows the microstructures of the mechanical alloying particles. It can be seen that the particles have irregular shapes, the size distribution is inhomogeneous, and the size of particles is in the range of $1-100 \mu \mathrm{m}$. The microstructures of ZL101 matrix
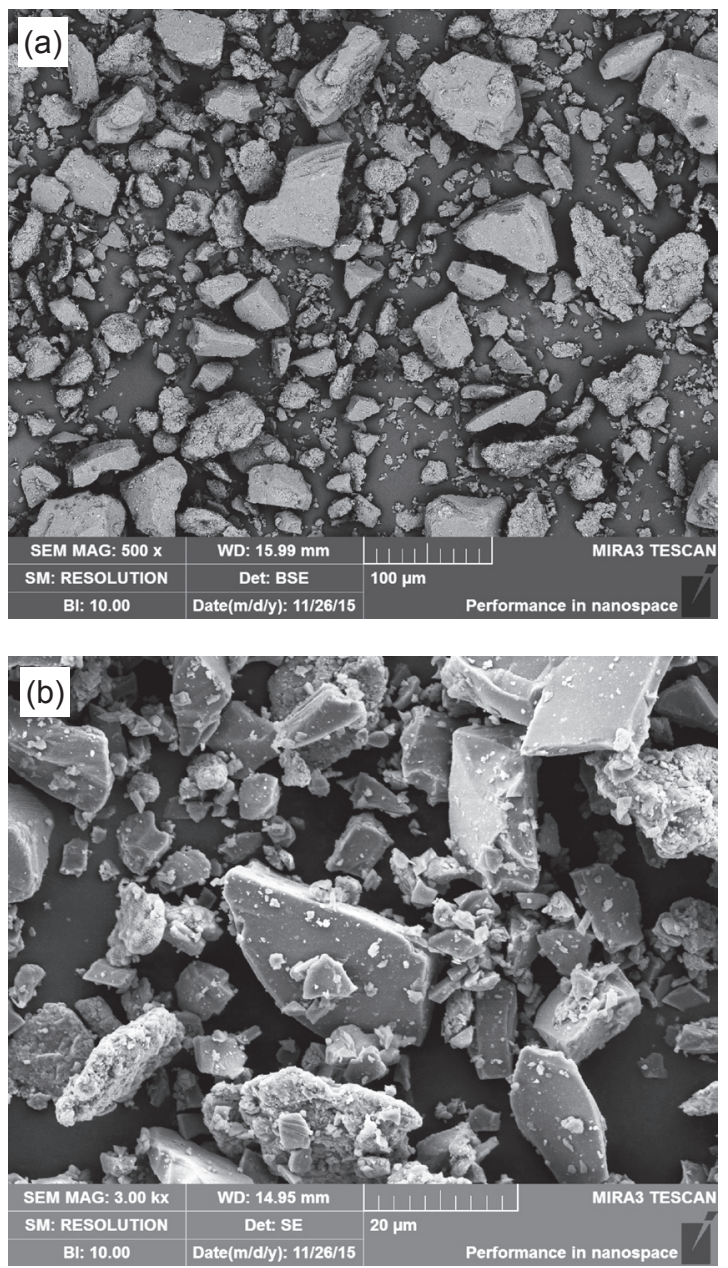

Fig. 2: BSE-SEM microstructure of mechanical alloying particles

composites and ZL101-Mg matrix composites are shown in Fig 3. As shown in Figs. 3b and 3c, the segregation phenomena and agglomeration phenomena of the alloying particles can be found in the ZL101 matrix composites; while, the agglomeration phenomena is not observed in the ZL101-Mg matrix composites.

Figure 4 shows the higher magnification microstructures of ZL101 matrix composites and ZL101-Mg matrix composites fabricated by semi-solid stirring pouring method. It can be seen that the microstructure of ZL101 matrix composite consists of large elongated primary grains and the eutectic phase is in the form of acicular structure. However, the addition of $\mathrm{Mg}$ converts large matrix grains into fine equiaxed matrix grains; eutectic phase into fine particles. Also, although some dispersed mechanical alloying particles are found within the grains, most of the mechanical alloying particles are distributed at grain boundaries in the ZL101/ ZL101-Mg matrix composites. This could be attributed to the "push" effect of the solidification front on the mechanical alloying particles. During the solidification, most particles in the liquid melt migrate towards the freezing front, resulting in most particles being distributed at grain boundaries ${ }^{[10]}$. While the mechanical alloying particles have no time to move before the melt solidification in some areas and they are engulfed by the grains ${ }^{[11]}$. So some dispersed mechanical alloying particles are found within the grains. 

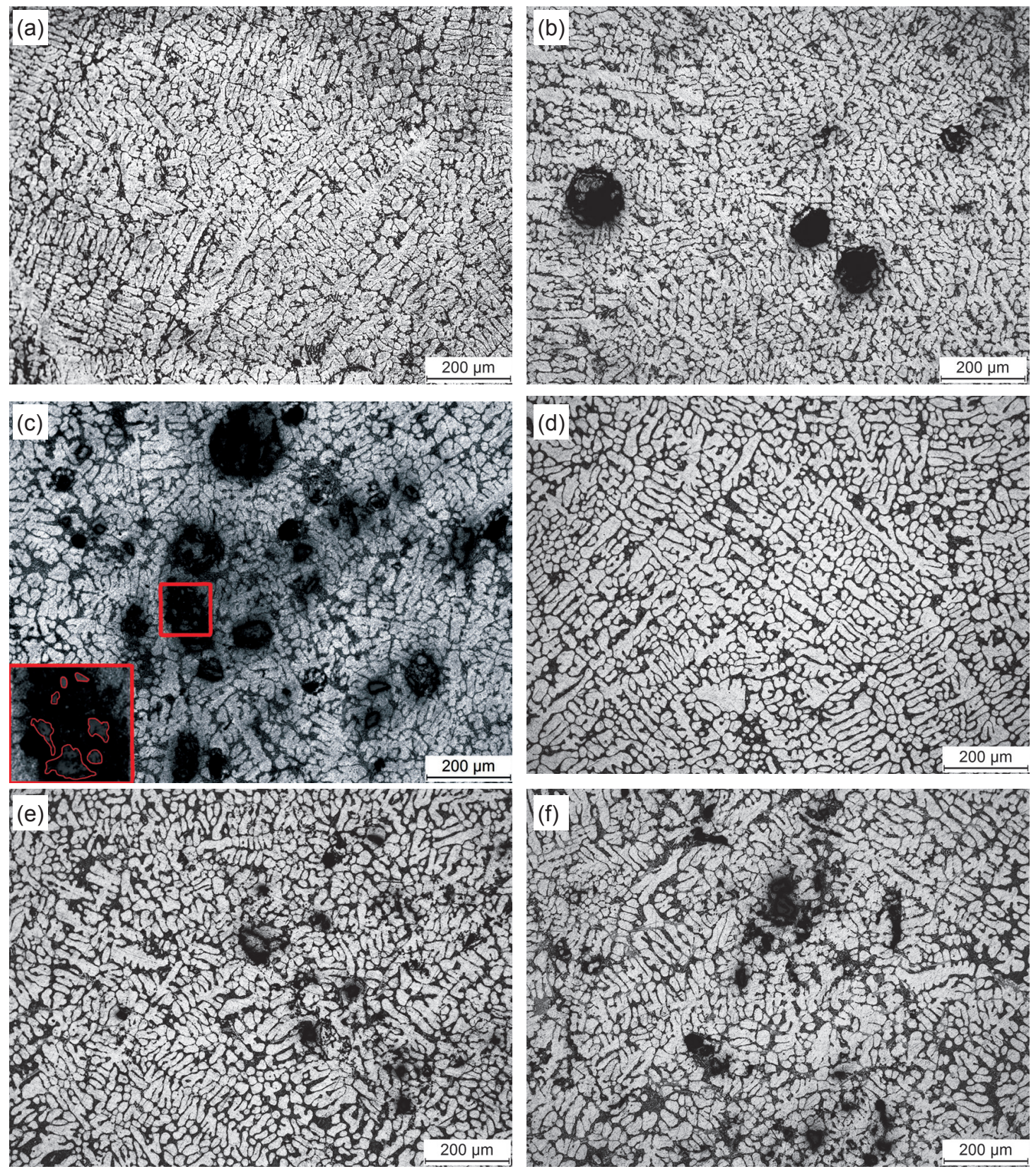

Fig. 3: OM micrographs of (a) ZL101 alloy; (b) ZL101 matrix composite with 1vol.\% SiC ; (c) ZL101 matrix composite with 3vol.\% SiC ; (d) ZL101-Mg alloy; (e) ZL101-Mg matrix composite with 1vol.\% SiC ; and (f) ZL101-Mg matrix composite with $3 \mathrm{vol}_{\mathrm{N}} \% \mathrm{SiC}_{\mathrm{p}}$

Figure 5 shows the grain size of ZL101 matrix and ZL101$\mathrm{Mg}$ matrix composites with different volume fractions of the mechanical alloying particles. It can be seen from Fig. 5 that the grain size of ZL101 alloy is $42.07 \mu \mathrm{m}$ while the grain size of ZL101 matrix composite is distinctly smaller than that of the matrix alloy. The grain size decreases to $41.28 \mu \mathrm{m}$ when the volume fraction is $1 \%$ and then sharply decreases to its minimum $32.02 \mu \mathrm{m}$ when the volume fraction of mechanical alloying particles is increased to $3 \%$. The mechanical alloying particles may act as heterogeneous nuclei for $\alpha$-Al phases, which could lead to increased occurrence of heterogeneous nucleation, and result in the finer grains. The influence of the volume fraction of mechanical alloying particles on the grain size of ZL101-Mg matrix composites is not significant. In Figs. 4 and 5, the grain size of the ZL101-Mg matrix exhibit obvious refinement compared with the ZL101 matrix.

Figure 6 shows the X-ray diffraction analysis results of the 3vol.\% ZL101 matrix composite and 3vol.\% ZL101-Mg matrix composite. The SEM morphology and EDS analyses of 3vol.\% ZL101-Mg matrix composite are shown in Fig. 7. Combining the XRD (Fig. 6) and EDS (Fig. 7) results, It can be found that the composites consist of $\alpha$-Al phase (arrow A in Fig. 7a), SiC phase (arrow B in Fig. 7a) and the $\mathrm{Al}_{3.2} \mathrm{Si}_{0.47}$ eutectic phase (arrow C in Fig. 7a).

\subsection{Mechanical properties}

The Vickers hardness and ultimate tensile strength of ZL101 matrix and ZL101-Mg matrix composites are shown in Fig. 8 and Fig. 9, respectively. It is obvious that the mechanical properties of ZL101 matrix composites are better than those 

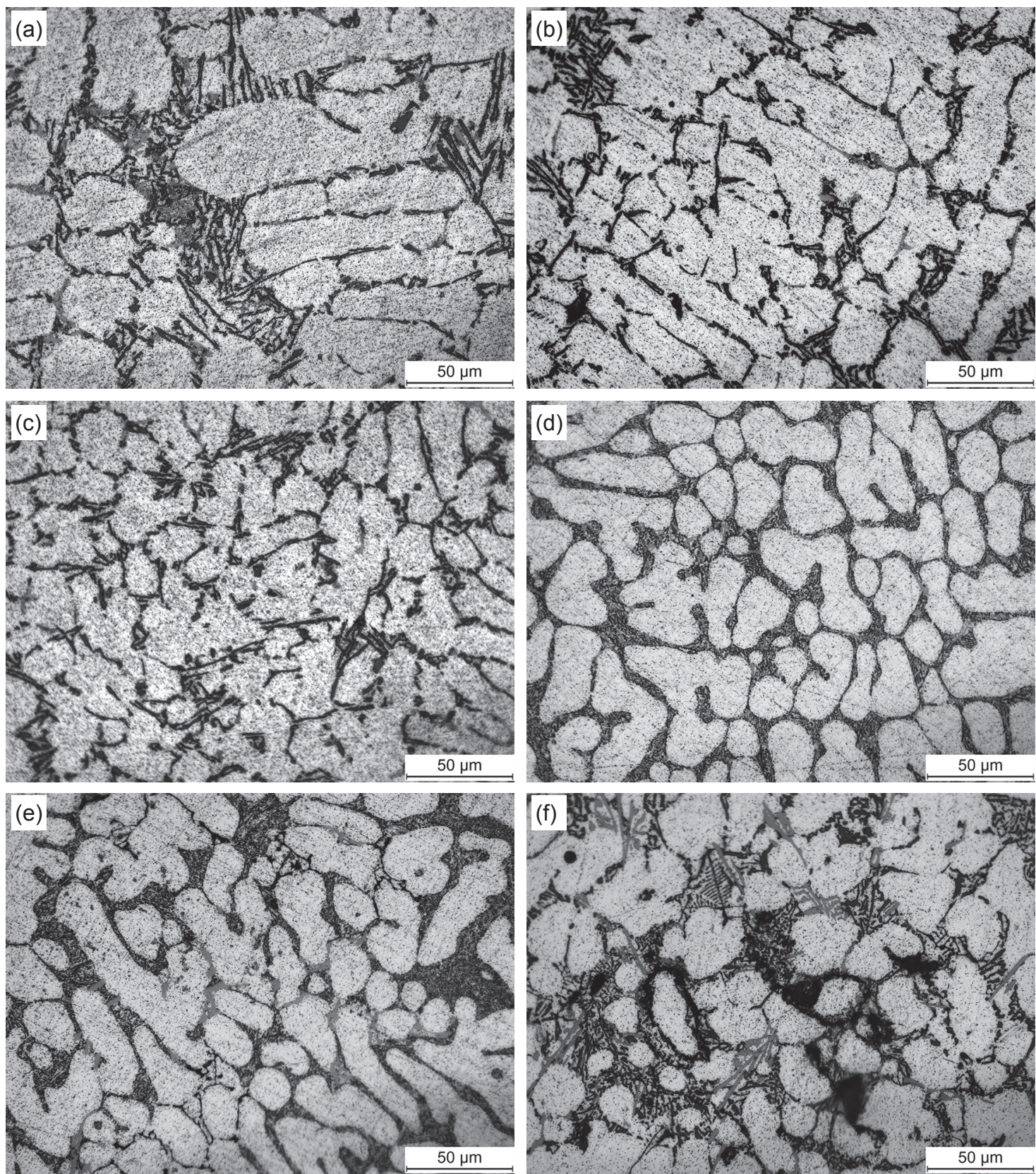

Fig. 4: Higher magnification: (a) ZL101 alloy; (b) ZL101 matrix composite with 1vol.\% SiC ; (c) ZL101 matrix composite with 3vol.\% SiC ; (d) ZL101-Mg alloy; (e) ZL101-Mg matrix composite with 1vol.\% SiC ; and (f) ZL101-Mg matrix composite with 3 vol. \% SiC

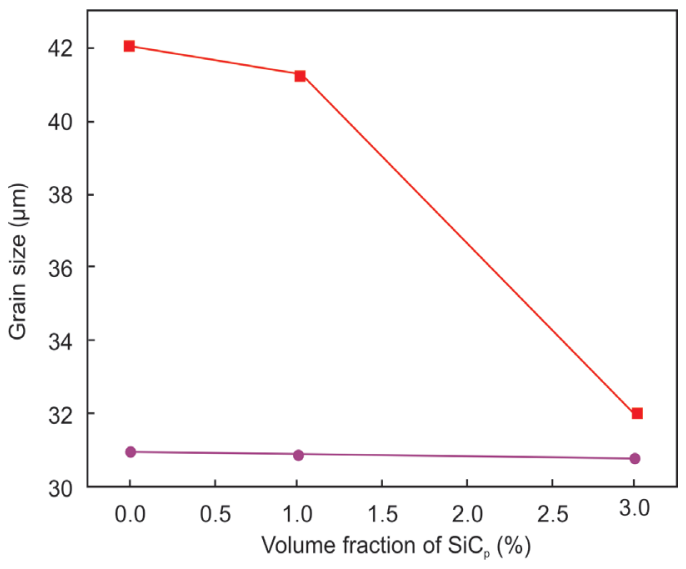

Fig. 5: Grain size of ZL101/ZL101-Mg matrix composites with different volume fractions of $\mathrm{SiC}_{\mathrm{p}}$

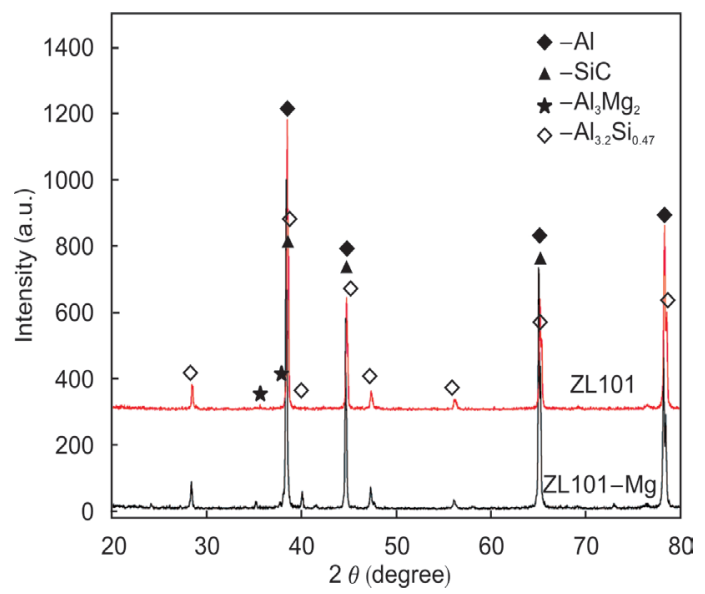

Fig. 6: XRD patterns of ZL101/ZL101-Mg matrix composites with $3 v_{0} . \% \mathrm{SiC}_{\mathrm{p}}$ 

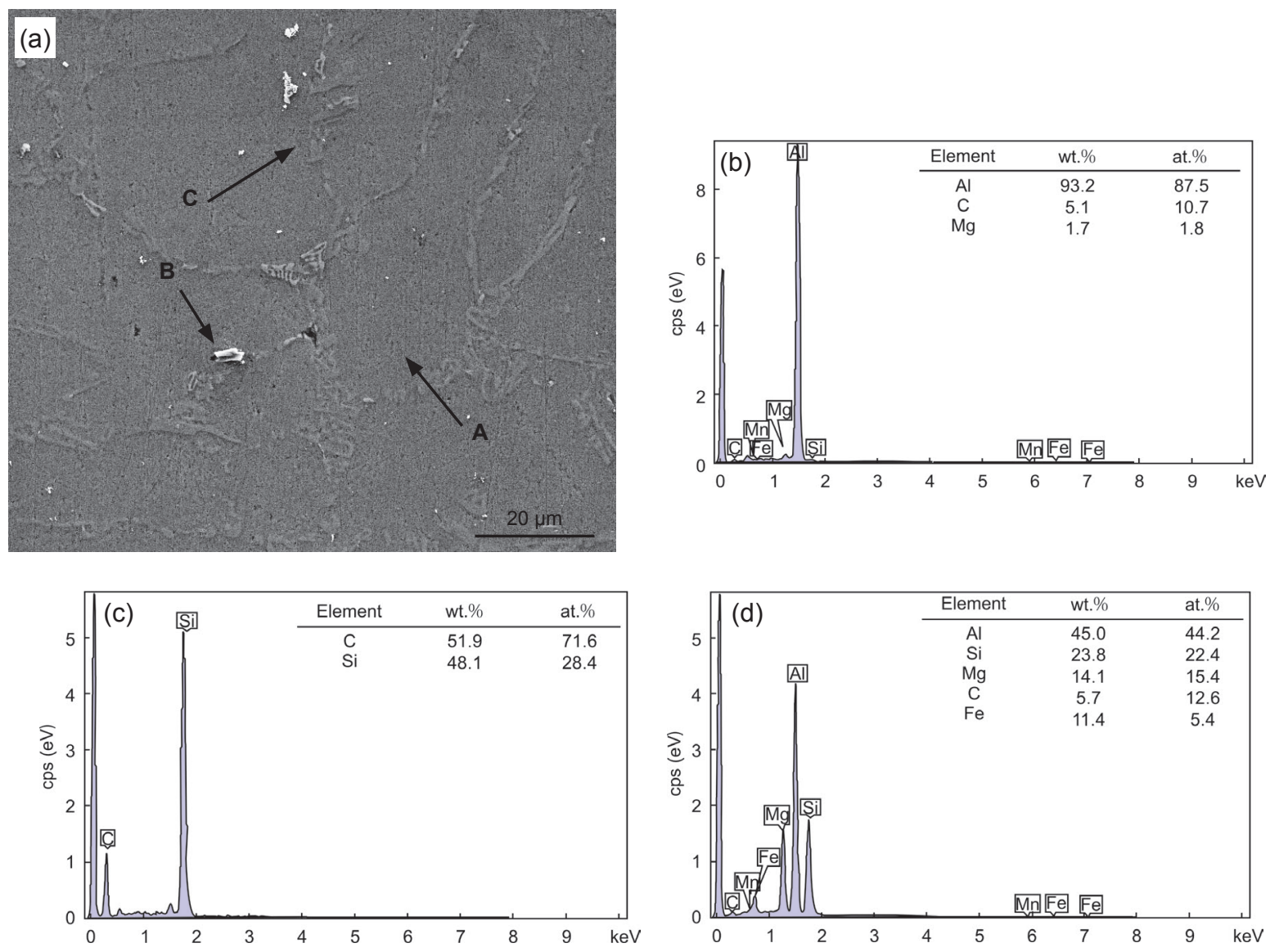

Fig. 7: SEM microstructures of ZL101-Mg matrix composite ( $\left.3 \mathrm{vol}^{\circ} \% \mathrm{SiC}_{\mathrm{p}}\right)(\mathrm{a})$ and EDS elemental analysis in the composite: (b) EDS in region $A$, (c) EDS in region $B$, and (d) EDS in region $C$

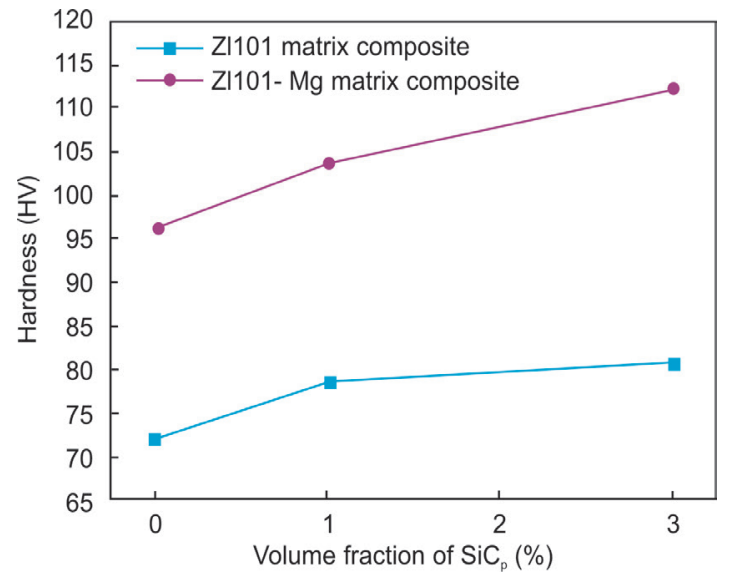

Fig. 8: Vickers hardness of ZL101/ZL101-Mg matrix composites

of the ZL101 alloy (71.98 HV \& $140 \mathrm{MPa})$. In addition, the Vickers hardness and the ultimate tensile strength of ZL101 matrix composites gradually increase with the rising volume fraction of mechanical alloying particles. The Vickers hardness and ultimate tensile strength sharply increase to $(78.32 \mathrm{HV} \&$ $151 \mathrm{MPa}$ ) when the volume fraction of mechanical alloying particles is up to $1 \%$ and then reaches their maximum $(80.7 \mathrm{HV}$ $\& 176 \mathrm{MPa}$ ) when the volume fraction of mechanical alloying particles increases to $3 \%$. The variation pattern of ZL101-

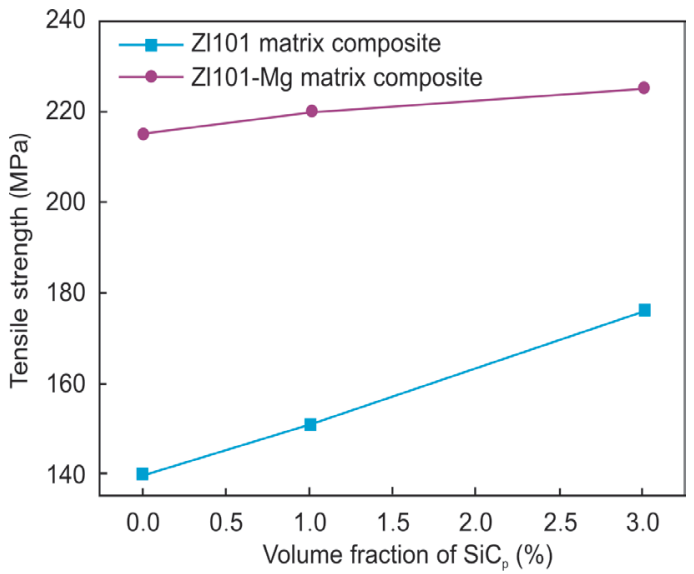

Fig. 9: Ultimate tensile strength of ZL101/ ZL101-Mg matrix composites

Mg matrix composites was similar to that of ZL101 matrix composites. The Vickers hardness and ultimate tensile strength of ZL101-Mg matrix are $96.28 \mathrm{HV} \& 215 \mathrm{MPa}$, reaching their maxima of $112.28 \mathrm{HV} \& 225 \mathrm{MPa}$ when the volume fraction of mechanical alloying particles is $3 \%$.

The improved Vickers hardness of ZL101 matrix composites and ZL101-Mg matrix composites can be attributed to two reasons. On the one hand, the high dislocations density which is located at the interface between the mechanical alloying 
particles and matrix (due to the different coefficient of thermal expansion between the matrix and the reinforcement particles) can strengthen the composite ${ }^{[12]}$. On the other hand, the fine grain strengthening of the matrix grains with the increasing volume fraction of mechanical alloying particles, results in the high hardness.

It should be noted that the Vickers hardness of the matrix in ZL101-Mg matrix composites is obviously higher when compared to the ZL101 matrix composites. This is due to the fact that the addition of $\mathrm{Mg}$ converts the large $\alpha$-Al grains into fine equiaxed $\alpha$-Al grains, and the effect of fine grain strengthening would help in improving the Vickers hardness of the composites. Moreover, the element of Mg can prevent aggregation of the mechanical alloying particles, so the crack will not form and extend from clusters of the mechanical alloying particles. As a result, the ultimate tensile strength of ZL101$\mathrm{Mg}$ matrix composite is obviously enhanced. Also, unmodified acicular silicon structure in ZL101 matrix composites acts as internal stress risers in the microstructure and provides an easy path for fracture, which is the primary reason for the low ultimate tensile strength of ZL101 matrix composites ${ }^{[13]}$.

\section{Conclusion}

The microstructure of ZL101 matrix composites consists of agglomerate mechanical alloying particles, large elongated primary grains and the acicular eutectic phases. However, the addition of $\mathrm{Mg}$ converts the agglomerate mechanical alloying particles into a dispersed distribution, large matrix grains into fine equiaxed ones and eutectic phase into fine particles. Therefore, the addition of $\mathrm{Mg}$ can greatly improve the Vickers hardness and ultimate tensile strength of ZL101 matrix composites. With an increase in the volume fraction of the mechanical alloying particles, the Vickers hardness and ultimate tensile strength of both the ZL101 matrix and ZL101-Mg matrix composites are gradually increased, and the grain size is gradually decreased. When the volume fraction of the particles is $3 \%$, the Vickers hardness and ultimate tensile strength reach their maxima, and the grain size is at a minimum.

\section{References}

[1] Eliosson J, Somclstrom R. Applications of aluminum matrix composites. Key Eng. Mater., 1995(1): 3-36.

[2] You Z Y, Wang Z, Hou L F, et al. Studies on Microstructure and Property of Material of $\mathrm{SiC}_{\mathrm{p}} / \mathrm{Gr} /$ Mixed and Reinforced Aluminum-Based Composites Prepared by Semi-Solid Pouring Method. Advanced Materials Research, 2011, 239: 116-121.

[3] Hong $\mathrm{Y}$, Xiaowu $\mathrm{H}$, Qiao N, et al. Aging behavior of nano-SiC reinforced AZ61 magnesium matrix composites. Research \& Development, 2011, 8(3): 269-273.

[4] Abarghouie S M R M, Reihani S M S. Aging behavior of a

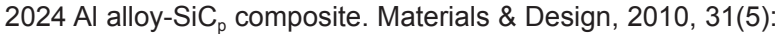
2368-2374.

[5] Jin P, Xiao B L, Wang Q Z, et al. Effect of solution temperature on aging behavior and properties of $\mathrm{SiC}_{\mathrm{p}} / \mathrm{Al}-\mathrm{Cu}-\mathrm{Mg}$ composites. Materials Science and Engineering A, 2011, 528(3): 1504-1511.

[6] Zhu Gang, Dong Puyun, Zhao Haidong. Microstructures and Properties of Squeezing Casting $10 \mathrm{SiC}_{\mathrm{p}}$ Reinforced A356 Composites with Different Particle Size. Special Casting \& Nonferrous Alloys, 2013, 33(10): 960-963. (In Chinese)

[7] Lu Jian, Gao Wenli, Su Hai, et al. Study on $\mathrm{SiC}_{\mathrm{p}} / \mathrm{A} 356$ Aluminum Matrix Composites Fabricated by Stir Casting. Foundry Equipment and Technology, 2009, 4:15-17. (In Chinese)

[8] Wang Hui, Wang Shuncheng, Zheng Kaihong, et al. Microstructures and Properties of $\mathrm{SiC}_{\mathrm{p}} / 6061$ Aluminum Matrix Composites Prepared by Semi-solid Stirring Casting. Special Casting \& Nonferrous Alloys, 2015, 35(6): 614-617. (In Chinese)

[9] Zhou Yongxin, Ma Bin, Lv Zhenlin. Influence of particle size on microstructures and wear properties of $\mathrm{SiC}_{\mathrm{p}}$ reinforced $\mathrm{Al}$ matrix composite. Ordnance Material Science and Engineering, 2011, 34(3): 18-20. (In Chinese)

[10 ]Hashim J, Looney L, Hashmi M S J. Particle distribution in cast metal matrix composites-Part I. Journal of Materials Processing Technology, 2002, 123(2): 251-257.

[11] Rohatgi P K, Yarrandi F M, Liu Y. Influence of solidification conditions on segregation of aluminum-silicon carbide particle composites. In: Proceedings of ASM International Conference on Cast Reinforced Metal Composites, Chicago, 1988, 249-255.

[12] Wang X J, Hu X S, Nie K B, et al. Hot extrusion of $\mathrm{SiC}_{\mathrm{p}} / \mathrm{AZ91}$ Mg matrix composites. Transactions of Nonferrous Metals Society of China, 2012, 22(8): 1912-1917.

[13] Basavakumar K G, Mukunda P G, Chakraborty M. Influence of grain refinement and modification on microstructure and mechanical properties of $\mathrm{Al}-7 \mathrm{Si}$ and $\mathrm{Al}-7 \mathrm{Si}-2.5 \mathrm{Cu}$ cast alloys. Materials Characterization, 2008, 59(3): 283-289. 